February 24, 2006

\title{
SCARCE COLLATERAL AND BANK RESERVES
}

Miquel Faig (University of Toronto) and Gregory Gagnon (University of Toronto)*

\begin{abstract}
If collateral for bank loans is scarce and as a result access to secured loans is restricted, the allocation of resources is inefficient. Anticipating future borrowing constraints, individuals over-invest in collateralized types of capital, whereas consumption and investment expenditures are inefficiently low while individuals are borrowing constrained. The dual counterpart of this misallocation of resources is inefficiently low interest rates. In this situation, bank reserves play a positive welfare role by increasing not only bank lending rates, but also, paradoxically, bank deposit rates. As a result, in economies with scarce collateral the optimal reserves requirement ratio is positive.
\end{abstract}

JEL Classification: E44, E50, G21.

Key words: collateral, banking, reserves, borrowing constraint, reserves requirement.

${ }^{*}$ We are thankful for the financial support received by M. Faig from SSHRC of Canada. Some of the material contained in this paper was part of the thesis of G. Gagnon. Corresponding author: Miquel Faig, 140 St. George Street, Suite 707, University of Toronto, Toronto (Ontario), Canada M5S 3G6, phone: 1-416-9780308, fax: 1-416-9785519, e-mail: mfaig@chass.utoronto.ca. 


\section{Introduction}

Collateral for bank loans is commonly found in credit contracts, and yet we can easily find indications that it is economically scarce. A large fraction of bank loans is secured with collateral, most typically with mortgages on real estate. Despite this common practice, unsecured loans, which often are linked to credit cards, are not rare. These unsecured loans pay large interest rate premia to cover not only high direct losses on defaults but also large monitoring and enforcement costs. Therefore, the recourse to unsecured loans by a sizable fraction of borrowers suggests that collateral for securing loans is scarce; otherwise, these borrowers would avoid the high interest rate premia on the unsecured loans. The purpose of our paper is to construct a tractable general equilibrium model to explore the consequences of the scarcity of collateral and the role of bank reserves in economies where collateral is scarce.

The model we advance adapts the income fluctuations problem by Foley and Hellwig (1975) and the related monetary model by Bewley (1980) to an economy with endogenous incomes and a banking sector. ${ }^{1}$ Following Woodford (1990), and to facilitate the analysis, we assume that income fluctuations are deterministic. To be precise, individuals receive output from personal production projects every two periods. Half the population receive their output in even periods, while the other half receive it in odd periods. Therefore, even though individual incomes vary over time, aggregate production does not.

The personal production projects that generate the income of individuals combine the labor of their owners with capital to produce output. The ownership of these projects is assumed to be non-transferable, and there is no other production in the economy. Therefore, there are no firms in the model. ${ }^{2}$ For example, we can think of an economy of yeomen who cannot be easily controlled by a large firm because their actions are not observable. These yeomen combine their labor with capital to produce crops. Some yeomen produce crops that mature in the summer while others produce crops that mature in the winter.

In this environment, we assume that credit is restricted because individuals do not trust each other, but it is not impossible, thanks to the pledge of collateral. Individuals are small

\footnotetext{
${ }^{1}$ For related banking models in a general equilibrium context see: Bernanke and Gertler (1987), Williamson (1987), Diaz-Gimenez, Prescott, Fitzgerald, and Alvarez (1992), Diamond and Dybvig (1983), and Holmström and Tirole (1998).

${ }^{2}$ If ownership of projects were transferable, firms would act as a credit market by owning a small scale-replica of the projects in existence in the economy.
} 
relative to the size of the economy, and they can hide their identity so that they face no penalty for defaulting on their loans. Hence, individuals have no access to unsecured loans; however, there is a type of capital that can be pledged in a credit contract to be used as collateral. Banks and only banks have the legal instruments to enforce these credit contracts. As a result, individuals can use both bank deposits and bank loans to transfer purchasing power from the periods they obtain output to the periods they do not. In equilibrium, individuals spend a fraction of the output of their projects to repay outstanding loans and another fraction to purchase bank deposits. In the periods without output, individuals spend their deposits and borrow with secured loans to finance their expenditures. The assets owned by banks include not only outstanding loans but also voluntary or mandatory reserves issued by the Central Bank. ${ }^{3}$

Our assumptions about credit markets and the untransferable ownership of production projects are similar to those found in recent papers by Kiyotaki and Moore (2002, 2006). (See their papers for an elaborate defence of these assumptions.) Their papers, however, analyze a different production structure with a single type of capital, and they do not study the role of bank reserves. Our paper is also similar to Faig (2000a), which studies the term structure of public debt in a version of the model without credit.

The conclusions of the paper can be summarized as follows. Investors anticipating to be credit constrained bias their investments towards types of capital useful as collateral. In equilibrium, collateral capital generates a lower marginal product than non-collateral capital. Hence, capital is allocated inefficiently. In addition, the inter-temporal allocation of consumption and investment expenditures is biased against the periods an individual faces borrowing constraints. In equilibrium, economies with scarce collateral are also economies with low lending and deposit rates. As long as borrowing is constrained by the need for collateral, bank reserves, either voluntary or mandatory, tend to raise not only lending rates but also, paradoxically, deposit rates. These higher rates discourage the over-accumulation of collateral because bank loans are less appealing with high lending rates, and self-financing is more appealing with high deposit rates. Also, the increase in deposit rates corrects the inter-temporal misallocation of consumption and investment expenditures. Therefore, increasing bank reserves through mandatory requirements is an effective second-best policy. A numerical example shows that the welfare benefits attained with this policy can be very large.

\footnotetext{
${ }^{3}$ Without loss of generality, one can also assume that banks can hold public debt. In the model, the public debt is a perfect substitute for reserves.
} 
The rest of the paper is organized as follows. Section 2 describes the model. Section 3 solves for the optimal behavior of individuals in an environment where borrowing is constrained by the need for collateral. Section 4 analyzes a steady state equilibrium with especial emphasis on the effect of the reserves-requirement ratio on interest rates. Section 5 discusses the welfare implications of the model. Finally, section 6 concludes.

\section{The Model}

The economy is populated by a large number of infinitely-living individuals, who make decisions at discrete times. These individuals are endowed with a non-transferable production technology, that allows the production of a homogeneous good which can be either consumed or invested. Production takes two periods to be completed; specifically, to obtain output at time $t+2$ individuals must invest quantities of the good in periods $t$ and $t+1$. These quantities are denoted as capital when invested at time $t$ and materials when invested at time $t+1$; both capital and materials fully depreciate once output is obtained. There are two types of capital: one can be used as collateral for bank loans, whereas the other cannot. The good cannot be stored without being invested as capital or materials.

The production technology is Cobb-Douglas:

$$
y_{t+2}=F\left(k_{0 t}, k_{1 t}, k_{2 t+1}\right) \equiv A k_{0 t}^{\alpha_{0}} k_{1 t}^{\alpha_{1}} k_{2 t+1}^{\alpha_{2}},
$$

where $y_{t+2}$ is the output obtained at time $t+2, k_{0 t}$ is the capital that can be used as collateral, $k_{1 t}$ is the other type of capital, and $k_{2 t+1}$ are materials. We assume that the production technology exhibits decreasing returns to scale, that is $\alpha_{0}+\alpha_{1}+\alpha_{2}<1$. This assumption can be motivated by the existence of an omitted fixed factor of production, for example the labor or the entrepreneurial effort of the individuals owning the technology. This fixed factor cannot be traded or more generally reallocated.

Although the production function $F$ is identical for all individuals, half the population owns a technology that starts the production cycle when $t$ is odd, while the other half owns a technology that starts production when $t$ is even. Therefore, at any time $t$ half the population is completing a production cycle and simultaneously investing in capital (stage one of production), while the other half of the population is investing in materials without receiving any output (stage two of production). This staggered structure of production cycles creates the necessity 
for inter-temporal trade across individuals. That is, when individuals are at stage two of production, they need output from individuals at stage one to consume and invest in materials.

Individuals do not have the means to monitor private credit arrangements. Likewise, they cannot enforce the payment of dividends if they invest in other individuals' technologies. However, in the economy there are commercial banks that have the means to monitor loans as long as they are backed by collateral. The only form of collateral in this economy is the capital of type $0, k_{0 t}$. Also, individuals can use bank deposits to self-finance their expenditures in periods without output. To do so, individuals sell part of their output at stage one of production for deposits, and they spend their deposits to buy goods during the second stage of the production cycle. The market of goods for deposits is competitive. Likewise, the individuals take as given the interest rate they earn on deposits $\left(r_{t}-1\right)$ and the interest rate they are charged on loans $\left(R_{t}-1\right)\left(R_{t}\right.$ and $r_{t}$ are gross returns).

The budget constraint of individuals differs depending on the stage of the production cycle they are in. Individuals who are at stage one of production at time $t$ allocate their wealth $x_{t}$ to first-stage consumption $c_{1 t}$, first-stage investments in the two types of capital $k_{0 t}$ and $k_{1 t}$, and deposits $m_{t}$ :

$$
x_{t}=c_{1 t}+k_{0 t}+k_{1 t}+m_{t} .
$$

These individuals at time $t+1$ are in the second stage of production. At this stage, their expenditure in second stage consumption $c_{2 t+1}$ and second stage investment in materials $k_{2 t+1}$ is limited by their deposits grossed with the interest paid on them, $r_{t+1} m_{t}$, plus the amount they borrow $b_{t+1}$ :

$$
b_{t+1}+m_{t} r_{t+1}=c_{2 t+1}+k_{2 t+1} .
$$

Borrowing is limited by the stock of collateral capital $k_{0 t}$ :

$$
b_{t+1} R_{t+1} \leq k_{0 t}
$$

Consumption, capital, materials, deposits, and loans must be non-negative:

$$
c_{1 t}, c_{2 t+1}, k_{0 t}, k_{1 t}, k_{2 t+1}, b_{t+1} \geq 0 \text {. }
$$

For the individuals who start their production cycles at $t+1$, analogous equations describe their budget constraints adjusting appropriately the time subscripts.

Individuals have time-separable preferences with a logarithmic instantaneous utility and a 
constant discount factor $\beta$ :

$$
V_{0}=\sum_{t=0}^{\infty} \beta^{t} \log \left(c_{i t}\right)
$$

The stages of production have no effect on preferences, but we distinguish consumption at the two stages of production because optimal consumption behavior depends on the stage of production. Therefore, the subscript $i$ in (6) alternates the values 1 and 2 as time progresses. That is, for individuals at stage one of production at time $t$, the stage-one value functions $V_{t}$ and $V_{t+2}$ are recursively related by the equation:

$$
V_{t}=\log \left(c_{1 t}\right)+\beta \log \left(c_{2 t+1}\right)+\beta^{2} V_{t+2}
$$

\subsection{The Banking Sector}

The banking system, comprised by a large number of commercial banks and a central bank, plays two roles in this economy. First, it acts as a clearing house for the system of payments. Second, it acts as the financial intermediary in the credit market. In detail, all individuals have a bank account in one of the many banks in the economy. All commercial banks are interconnected at no cost through a clearing payments network. When a transaction in the market of goods for money occurs, the buyer transfers the value of the transaction from his or her bank account to the bank account of the seller. The balance of a bank account can be positive or negative. When the balance is positive, we call it a deposit owned by the holder of the account. When the balance is negative, we call it a loan owed by the holder of the account. For simplicity, we assume that all these bank activities require no real resources.

The central bank accepts deposits from commercial banks, and these deposits are denoted reserves and cannot be negative. In addition, the central bank may establish a statutory

minimum reserves - deposit ratio, $\bar{\theta}$, greater than zero. Commercial banks decide whether or not to hold reserves above the statutory minimum, as the central bank pays no interest to the commercial banks on their reserves. Also, the central bank has no taxing power, and there is no other branch of government to subsidize the activities of the central bank.

The market for deposits and loans is assumed to be competitive and the banking technology yields constant returns, so in equilibrium banks must earn zero profits. Hence, the gross return accruing to the commercial banks from their portfolio of loans and reserves must be equal to the gross return earned by depositors. Denoting $\theta_{t}$ the ratio of reserves (statutory and voluntary) 
to deposits at time $t$, the zero profit condition can be stated as follows:

$$
r_{t}=\theta_{t}+\left(1-\theta_{t}\right) R_{t}
$$

The left hand side of (8) is the gross return earned by depositing one dollar. The right hand side is the return that the commercial bank receiving the dollar gets by holding $\theta_{t}$ cents as reserves and lending $1-\theta_{t}$ at a gross rate of return $R_{t}$. Since banks can choose to hold reserves at a gross return equal to one, we have $R_{t} \geq 1$. Hence, equation (8) implies $r_{t} \leq R_{t}$.

In addition to the zero-profit condition (8), the rates of return $r_{t}$ and $R_{t}$ must also equilibrate the credit market; that is, the supply of loanable funds by banks must be equal to the demand for loans by individuals:

$$
\left(1-\theta_{t}\right) m_{t}=b_{t}
$$

The term $\left(1-\theta_{t}\right) m_{t}$ is the fraction of deposits available for loans for each individual at stage one of production. The term $b_{t}$ is the loans made by each individual at stage two of production. Since there are the same number of individuals at stages one and two, equation (9) implies equilibrium in the credit market.

\section{Optimal Behavior of Individuals}

Without loss of generality, we describe the optimal choices of an individual that at time $t$ is at stage one of production. Recursively, this individual takes the gross interest rates $\left\{R_{t}, r_{t}\right\}_{t=0}^{\infty}$ as given and chooses $\left\{c_{1 t}, c_{2 t+1}, k_{0 t}, k_{1 t}, k_{2 t+1}, b_{t+1}\right\}$ to maximize (7) subject to (2) to (5) and a standard Non-Ponzi game condition. Conveniently the budget constraints (2) and (3) can be combined into the following two-period budget constraint:

$$
x_{t}=c_{1 t}+k_{0 t}+k_{1 t}+r_{t+1}^{-1}\left(c_{2 t+1}+k_{2 t+1}-b_{t+1}\right) .
$$

Since the objective is concave and the constraints convex, the individual maximization problem has a unique solution.

When the non-negativity constraints (5) are not binding, the first-order conditions for the 
individual choice problem are:

$$
\begin{gathered}
c_{1 t}^{-1}=\beta r_{t+1} c_{2 t+1}^{-1}, \\
c_{1 t}^{-1}=\beta^{2} F_{1 t+2} c_{1 t+2}^{-1}, \\
r_{t+1} F_{2 t+2}=F_{1 t+2}, \\
F_{0 t+2}+\left(F_{2 t+2}-R_{t+2}\right) R_{t+2}^{-1}=F_{1 t+2}, \text { and } \\
F_{2 t+2} \geq R_{t+2} \text { and }\left(k_{0 t}-b_{t+1} R_{t+2}\right)\left(F_{2 t+2}-R_{t+2}\right)=0 .
\end{gathered}
$$

For notational convenience, we use $F_{i t+2}$ to denote the partial derivatives of $F$ with respect to $k_{i t}, i=0$ and 1 , and $F_{2 t+2}$ to denote the partial derivative of $F$ with respect to $k_{2 t+1}$. (Both capital invested at $t$ and materials invested at $t+1$ mature at $t+2$.) Condition (11) equates the utility of consuming one unit of output immediately after completing a production cycle (stage one) with the utility of selling this unit of output for deposits to increase consumption next period. Condition (12) equates the utility of consuming one unit of output at stage one with the utility of investing this unit of output in capital $k_{1 t}$ to increase consumption two periods later. Condition (13) equates the return of investing one unit of output in capital $k_{1 t}$ with the compound return of investing the value of this unit of output in deposits for one period and rolling this investement into materials $k_{2 t+1}$ for another period. Condition (14) equates the return of investing in the two types of capital. The return of investing in $k_{1 t}$ is simply the marginal product of this type of capital. The return of investing in $k_{0 t}$ includes not only its marginal product, but also the benefit of being able to increase borrowing at the second stage of production. For each unit of $k_{0 t}$ borrowing can be increased by $R_{t+2}^{-1}$ units because collateral must cover both principal and interest. The benefit of borrowing one unit of output is the difference between the rate of return on second-stage investments $F_{2 t+2}$ and the lending rate $R_{t+2}$. Finally, (15) is the Kuhn-Tucker condition associated with the borrowing constraint (4). This borrowing constraint must be strictly binding, and so $k_{0 t}=b_{t+1} R_{t+2}$, when $F_{2 t+2}>R_{t+2}$. Conversely, the two returns $F_{2 t+2}$ and $R_{t+2}$ must be equal, when the borrowing capacity is not exhausted.

\section{Steady-State Equilibrium}

Definition: An equilibrium of the economy described in Section 2 is a sequence $\left\{c_{1 t}, c_{2 t+1}, k_{0 t}, k_{1 t}, k_{2 t+1}, \theta_{t}, b_{t+1}, r_{t}, R_{t}\right\}_{t=0}^{\infty}$ which is consistent with the optimal behavior of in- 
dividuals and commercial banks, the zero profit condition for commercial banks (8), and the market clearing condition (9).

Definition: A steady-state equilibrium is an equilibrium which satisfies:

$\left(c_{1 t}, c_{2 t+1}, k_{0 t}, k_{1 t}, k_{2 t+1}, y_{t}, \theta_{t}, b_{t+1}, m_{t}, r_{t}, R_{t}\right)=\left(c_{1}, c_{2}, k_{0}, k_{1}, k_{2}, y, \theta, b, m, r, R\right)$ for all $t \geq 0$.

For simplicity, the rest of this paper focuses on the analysis of steady-state equilibria, so from now on all time subscripts are dropped. The first-order conditions (12) to (14) imply that the gross return from investing in $k_{0}$ or $k_{1}$ for two periods, and the compounded return of investing in deposits for one period and $k_{2}$ in the next are all equal to $\beta^{-2}$ in a steady state. The gross return of $k_{1}$ is $F_{1}$. The compounded return of investing in deposits and $k_{2}$ is $r F_{2}$. Finally, the total return of investing in $k_{0}$ includes its marginal product in physical production and its marginal benefit when used as collateral. Using (12) to (15), we can express the total return of $k_{0}$ as a product $\rho F_{0}$ where $\rho$, which we call the collateral benefits factor, is equal to:

$$
\rho=\max (1, \hat{\rho}), \quad \text { where } \hat{\rho}=\left(1+\beta^{2}-r^{-1} R^{-1}\right)^{-1}
$$

When collateral is sufficiently abundant, the borrowing constraint (4) is not binding, so $\rho=1$. When the borrowing constraint is binding, the collateral benefits factor is greater than one and inversely related to both $R$ and $r$. The reason for this inverse relationship is the following. Borrowing from banks is less attractive at a higher lending rate, and self-financing with deposits is more profitable at a higher deposit rate.

With the definition of $\rho$ in (16), a steady-state equilibrium is a solution to the following system of equations, which combines the first-order conditions (12) to (15), the definition of the production technology, the market-clearing conditions, the budget constraint, the zeroprofit condition (8), and the complementary conditions to the inequality constraints imposed on borrowing and bank reserves:

$$
\begin{gathered}
c_{2}=\beta r c_{1} \\
k_{0}=\alpha_{0} \beta^{2} y \rho \\
k_{1}=\alpha_{1} \beta^{2} y \\
k_{2}=\alpha_{2} \beta^{2} y r
\end{gathered}
$$




$$
\begin{gathered}
c_{1}+c_{2}+k_{0}+k_{1}+k_{2}=y \\
(1-\theta) m=b \\
m=\left(c_{2}+k_{2}-b\right) r^{-1} \\
y=A k_{0}^{\alpha_{0}} k_{1}^{\alpha_{1}} k_{2}^{\alpha_{2}} \\
r=\theta+(1-\theta) R \\
\left(k_{0}-b R\right)(1-\rho)=0 \\
(\theta-\bar{\theta})(R-1)=0
\end{gathered}
$$

The existence of an admissible solution to the system (16) to (27) and the nature of this solution is described in Proposition 1. In this proposition, we use the following classification of equilibrium types:

Type A: banks hold excess reserves and borrowing is constrained $\left(\theta>\bar{\theta}\right.$ and $\left.k_{0}=b R\right)$.

Type B: banks hold no excess reserves and borrowing is constrained $\left(\theta=\bar{\theta}\right.$ and $\left.k_{0}=b R\right)$.

Type C: banks hold no excess reserves and borrowing is not constrained $\left(\theta=\bar{\theta}\right.$ and $\left.k_{0}>b R\right)$.

Proposition 1 A unique steady-state equilibrium exists for the parameter values assumed in the description of the model in Section 2. The nature of this equilibrium depends on

$$
\hat{\alpha}_{0}=\alpha_{0} \frac{\beta^{2}}{1-\alpha_{1} \beta^{2}+\alpha_{2} \beta},
$$

and two positive numbers: $\psi_{0}$ and $\psi_{1}\left(\psi_{0}<\psi_{1}\right)$, which depend on $\beta$ and $\bar{\theta}$ as specified in the Appendix.

If $\hat{\alpha}_{0}<\psi_{0}$, then the equilibrium is type $\boldsymbol{A}, r=R=1$, and $\rho>1$.

If $\hat{\alpha}_{0} \in\left[\psi_{0}, \psi_{1}\right]$, then the equilibrium is type $\boldsymbol{B}, r \in\left[1, \beta^{-1}\right], R \geq 1$, and $\rho \geq 1$.

If $\hat{\alpha}_{0}>\psi_{1}$, then the equilibrium is type $C, r \in\left(1, \beta^{-1}\right), R \in\left(\beta^{-1}, \beta^{-2}\right)$, and $\rho=1$.

If the weight of $k_{0}$ in the production function is low, as measured by $\hat{\alpha}_{0}$, collateral is scarce, and so borrowing is constrained (equilibrium types A and B). This borrowing constraint implies that individuals have a low effective demand for loans and consequently a low gross lending rate $R$. Simultaneously, individuals seek to compensate for their limited ability to borrow with a high reliance on self-finance and hence a high demand for deposits. This high demand tends to depress $r$. If $\hat{\alpha}_{0}$ is very low, the lending rate falls to the point where banks get the same return investing in loans and reserves (equilibrium type $\mathrm{A}$ ), so $R=1$. Then, banks hold excess reserves. 
In contrast, if $\hat{\alpha}_{0}$ is high, households invest sufficiently large amounts on $k_{0}$, so borrowing is not constrained by the available collateral (equilibrium type C). As a result, both the demand for loans and the lending rate are high. In this case, $R$ is guaranteed to be above 1 , so banks hold no excess reserves.

The most interesting equilibrium type to study the role of mandatory bank reserves is type B. In the type $\mathrm{C}$ equilibrium, borrowing is not constrained, so the economy has no shortage of liquidity and, as it will become apparent below, there is no welfare enhancing role of mandatory bank reserves. In the type A equilibrium, the minimum reserve requirement is not binding, so it plays no role. Moreover, voluntary reserves in this equilibrium are only useful because of the absence of storage in the model. In contrast, in the type B equilibrium, there is going to be a welfare enhancing role of mandatory bank reserves, and this role is robust to the introduction of storage because, as Proposition 1 states, in this equilibrium deposits earn a positive net interest rate, so nobody would choose to store goods even if they could.

\subsection{Changing the Reserves-Requirement Ratio}

The following proposition summarizes how reserves-requirement policies affect the space of parameters for which borrowing is constrained, and how these policies affect the deposit and lending rates in a steady-state equilibrium:

Proposition 2 An increase in the reserves-requirement ratio $\bar{\theta}$ reduces the two bounds $\psi_{0}$ and $\psi_{1}$ in Proposition 1 that determine the nature of the steady-state equilibrium. Consequently, banks may stop holding excess reserves as a result of an increase in $\bar{\theta}$ (a shift from type A to type $B$ equilibrium), or borrowing constraints may cease to be binding (a shift from type $B$ to type $C$ equilibrium). As long as the steady state is type $A, R=r=1$, interest rates are insensitive to changes in $\bar{\theta}$. As long as the steady state is type $B$, both the deposit and the lending rates are increasing with $\bar{\theta}$. Finally, as long as the steady state is type $C$, the lending rate rises with $\bar{\theta}$, but the deposit rate falls.

If $\bar{\theta}$ is large, banks are less likely to hold excess reserves; that is, the range of parameters in which type A equilibrium exists is smaller. As long as banks hold no excess reserves, an

increase in $\bar{\theta}$ reduces the supply of loanable funds by banks, so $R$ increases. Higher lending rates, make borrowing by households less attractive. Consequently, the range of parameters in which borrowing is constrained is smaller. Paradoxically, the response of deposit rates to 
increases in $\bar{\theta}$ is non-monotonic. If borrowing is unconstrained, we have the familiar result from partial equilibrium analyses: An increase in $\bar{\theta}$ can be viewed as an implicit tax on bank lending which partly falls on borrowers ( $R$ increases) and partly falls on lenders ( $r$ falls). However, if borrowing is constrained, the increase in $\bar{\theta}$ has also the effect of increasing liquidity in the banking system by increasing bank reserves. For a given amount of collateral capital $k_{0}$, an increase in bank reserves increases the amount of deposits offered by banks. To attract this larger amount of deposits, banks must increase the deposit rate ( $r$ increases). Hence, the paradox: If borrowing is constrained, increasing the reserves requirement ratio increases not only the lending rate but also the deposit rate.

\section{Welfare}

This section shows that bank reserves, even when imposed through mandatory reserves requirements, have positive welfare effects if collateral is scarce.

To understand the welfare implications of bank reserves, it is useful to start with a description of the first-best (symmetric) allocation. This allocation maximizes a utilitarian welfare function subject to the resource constraints in the economy. In the steady state, the first-best allocation has the following properties:

(1) All individuals consume the same amount at all times.

(2) All investments have the same one-period gross return, which is equal to $\beta^{-1}$.

The first-best allocation is attained as a competitive equilibrium with a zero-reserves requirement if collateral is sufficiently abundant so that borrowing is unconstrained. In this situation, not only bank reserves are unnecessary to attain the first best, but imposing positive reserves is also detrimental from a welfare perspective. In this case, a positive reserves requirement has the following two consequences. First, it lowers the bank deposit rate, so depositors substitute present consumption for future consumption, that is $c_{1}>c_{2}{ }^{4}$. Second, it raises the bank lending rate, so borrowers demand a high return on investments which at the margin are financed with loans, that is $F_{2}>\beta^{-1} .^{5}$ The welfare implications of bank reserves are very different if collateral is scarce.

When collateral is scarce, a steady-state equilibrium without required reserves presents inefficiencies in the following three margins:

\footnotetext{
${ }^{4}$ This is the direct consequence of $r<\beta$ and condition (11).

${ }^{5}$ This inequality results from $R>\beta^{-1}$ and condition (15).
} 
(1) Bias against second stage consumption: $c_{2}<c_{1} \cdot^{6}$

(2) Bias against second stage investment: $F_{2}>\beta^{-1}$. $^{7}$

(3) Bias in favor of investing in collateral: $F_{0}<\beta^{-2} .8$

These three margins of inefficiency are the dual counterpart of low interest rates; that is, if borrowing is constrained in the absence of required reserves, then $R=r<\beta^{-1}$. This situation corresponds to equilibrium types A and B in Proposition 1. In a type A equilibrium, bank reserves are held voluntarily. In their absence, net interest rates would be negative $(R=r<1)$ because of the extremely low demand for loans backed with suitable collateral. Negative net interest rates would only worsen the three margins of inefficiency (1) to (3). Hence, in type A equilibrium bank reserves play a positive efficiency role similar to the role played by outside liabilities in the related models by Bewley(1980), Hugget(1993), and Aiguari(1994). This role, though, would be eliminated in the presence of storage. More surprisingly, even when reserves are imposed through a positive-reserves requirement they can be welfare enhancing, and it this case the presence or absence of storage is irrelevant.

In a type $\mathrm{B}$ equilibrium, net interest rates are positive, but they are inefficiently low in the absence of required reserves: $1<R=r<\beta^{-1}$. Moreover, an increase in the reserves requirement ratio, $\bar{\theta}$, increases both the deposit and the lending rate (Proposition 2). As a result, the increase in $\bar{\theta}$ tends to correct the three inefficiencies listed in the previous paragraph. The increase in the deposit rate gives an incentive to individuals at the first stage of their project to postpone both consumption and investment. Hence, the ratios $c_{2} / c_{1}$ and $k_{2} / k_{1}$ increase with $\bar{\theta}$, which ameliorates the inefficiencies (1) and (2) listed above. Moreover, with a higher $\bar{\theta}$ individuals have a weaker incentive to invest in collateral, because loans are more expensive ( $R$ has increased) and self-financing is more profitable ( $r$ has also increased). Consequently, the ratio $k_{0} / k_{1}$ falls with $\bar{\theta}$ which ameliorates the inefficiency (3).

Changes in the reserves-requirement ratio have an effect not only on the composition but also on the aggregate stock of capital in the economy. Therefore, the welfare consequences of changes in $\bar{\theta}$ must take into account the costs and benefits of transitions across steady states, which are analytically untractable. For this reason, we rely on numerical methods to illustrate the overall effects on welfare of changing $\bar{\theta}$. Our findings are summarized in Figure 1.

To construct Figure 1, we calculated numerically the equilibrium paths of economies for

\footnotetext{
${ }^{6}$ This is the direct consequence of $r<\beta$ and condition (11)

${ }^{7}$ This inequality results from $r<\beta^{-1}$ and condition (13).

${ }^{8}$ This inequality follows from $R<\beta^{-1}<F_{2}$ and condition (14). Note that $k_{0}$ is invested for two periods.
} 
which the reserves requirement ratio is raised from $\bar{\theta}_{0}=0$ to $\bar{\theta}_{1}>0$. To be precise, starting conditions in period 0 are those of a steady state with $\bar{\theta}_{0}=0$. In period 1 , a new policy on the reserves requirement is announced. From then on, individuals have perfect foresight. To avoid a major redistribution of wealth during the transition, the policy change is spread over two periods. In period 1 , the reserves requirement increases immediately to $\bar{\theta}_{1} / 3$. In period 2 , the reserves requirement increases to the new steady-state value $\bar{\theta}_{1}$. In all the numerical examples we conducted, we found that the utility for the two types of individuals in our economies increases as long as $\bar{\theta}_{1}$ is not too large. ${ }^{9}$

In Figure 1, we report the welfare gains of raising $\bar{\theta}$ for $\beta=0.96$ and $\alpha_{0}=\alpha_{1}=\alpha_{2}=0.2$. These welfare gains are measured using the conventional equivalent variation of consumption; that is, we measure welfare using the average percentage increases of steady-state consumption with $\bar{\theta}_{0}=0$ that are necessary to achieve the utility of the individuals in our equilibrium paths. In the numerical example of Figure 1, welfare increases monotonically with the reservesrequirement ratio until $\bar{\theta}_{1}=0.22$. Increasing from $\bar{\theta}_{0}=0$ to $\bar{\theta}_{1}=0.22$ is equivalent to an average increase of 4.7 per cent of steady-state consumption. For reserves requirements higher than 0.22 , borrowing is not constrained by collateral any more. Therefore, marginal increases of $\bar{\theta}_{1}$ beyond 0.22 are not welfare improving. However, the decline in welfare for these marginal increases is small relative to the sharp marginal welfare improvements attained by rising $\bar{\theta}$ at levels below 0.22 .

Our welfare analysis presumes that the Central Bank has neither taxing powers nor that it is required to finance other branches of Government, so that the net return on reserves is zero in the steady state. If the Central Bank could rely on lump-sum taxation, the first best could be achieved by subsidizing the interest on bank reserves with lump-sum taxes and in so doing attain $R=r=\beta^{-1}$ without having to impose mandatory reserve requirement. ${ }^{10}$ Equivalently, the Central Bank could issue public debt, which banks could hold instead of reserves, and subsidize the interest on public debt to achieve the same outcome. These possibilities illustrate that when liquidity in the economy is scarce, the elimination of reserve requirements is not equivalent to payment of interest on bank reserves.

\footnotetext{
${ }^{9}$ During the transition, bank reserves increase, so the Central Bank experiences current profits which we assume are transferred lump-sum to deposit holders.

${ }^{10}$ As pointed out by Bewley (1983) and Faig (2000b), lump-sum taxation is problematic with unobservable shocks to endowments or to the return on capital of the individual projects.
} 


\section{Conclusion}

A sizable fraction of the population use their credit cards to borrow at interest rates that are several times those they could be paying in a secured loan, which suggests that at least for these individuals collateral is scarce. In our model, the interest rates on unsecured loans is infinity (that is, they are not available), but we conjecture that our results are robust in the presence of expensive unsecured loans. In either case, investors anticipating to be constrained on secured loans by lack of collateral have an incentive to bias their investments towards collateralized capital. As a result, capital in the economy is misallocated: different types of capital with the same risk characteristics yield in equilibrium different marginal products. In addition, consumption and investment in periods with constrained borrowing has to be cut down, resulting in an inter-temporal misallocation of expenditures.

The misallocation of resources due to the scarcity of collateral is reflected in the equilibrium interest rates. The scarcity of collateral not only restricts the demand for bank loans, but also expands the demand for bank deposits to self-finance expenditures when secured loans are restricted. Both the restriction on the demand for loans and the expansion of the demand for deposits depress interest rates. Therefore, economies with scarce collateral are characterized by low lending and deposit rates. In the steady-state equilibrium we describe, these rates are below the subjective discount rate in the absence of required reserves.

The scarcity of collateral implies a positive role for bank reserves. Bank reserves restrict the loans banks can supply for a given amount of deposits. As long as borrowing is constrained, bank reserves, either voluntary or mandatory, tend to raise both lending and deposit rates. This increase in interest rates discourages the over-accumulation of collateral capital because bank loans are less appealing at a higher lending rate, and because self-financing is more appealing with a higher deposit rate. Also, the increase in deposit rates corrects the inter-temporal misallocation of expenditures. In a numerical example, we showed that the welfare benefits of bank reserves can be large. However, our model was designed to be analytically tractable, so the model should be extended in several dimensions before a more precise calibration can be performed. For example, in future work one may wish to incorporate physical resource costs for bank activities and a more flexible production technology.

The imposition of reserves requirements are not the only policy tool to address the inefficiencies caused by the scarcity of collateral. The payment of interest on government liabilities 
(public debt or bank reserves) can play a similar role. However, government liabilities can only earn a positive real interest rate in a steady state if they are subsidized with taxes. In future research, it would be interesting to compare the welfare implications of imposing reserves requirements versus the welfare implications of subsidizing the interest on government liabilities with realistic costs of taxation. 


\section{Appendix}

Lemma 1: Given that $\beta \in(0,1)$ and $\bar{\theta} \in[0,1)$. The quadratic function $f(r)=r^{2}-\theta r-$ $(1-\theta) \beta^{-2}$ has a unique positive root, $\hat{r}$, with the following properties: $\hat{r} \in\left(1, \beta^{-1}\right), d \hat{r} / d \bar{\theta}<0$, and

$$
\hat{r}=\frac{1}{2}\left[\theta+\beta^{-1} \sqrt{\bar{\theta}^{2} \beta^{2}+4(1-\bar{\theta})}\right] .
$$

Proof: Direct evaluation implies: $f(1)=(1-\bar{\theta})\left(1-\beta^{-2}\right)<0, f\left(\beta^{-1}\right)=\bar{\theta}\left(\beta^{-2}-\beta^{-1}\right)>$ 0 . Since $f$ is continuous, there is $\hat{r} \in\left(1, \beta^{-1}\right)$ such that $f(\hat{r})=0$. Because $f(r)$ is a quadratic polynomial, the product of its two roots must be equal to the term $-(1-\bar{\theta}) \beta^{-2}$ and so be negative. Since $\hat{r}>0$, the other root of $f(r)$ must be negative. The implicit function theorem implies

$$
\frac{d \hat{r}}{d \bar{\theta}}=-\frac{\beta^{-2}-\hat{r}}{2 \hat{r}-\bar{\theta}}<0
$$

Finally, (29) follows from the standard formula for the roots of quadratic equations.

Lemma 2: As long as $\theta=\bar{\theta}$, equations (16), and (25) define an implicit mapping of $r$ onto $\rho$ with the following properties: $\rho=1$ if $r \geq \hat{r}$ (as defined in Lemma 1), $\rho=\beta^{-2}$ if $r=1$, and $\rho$ is a strictly decreasing function of $r$ if $r \in(1, \hat{r})$.

Proof: Using $\theta=\bar{\theta},(25)$, and (16), we have

$$
\hat{\rho}=\left(1+\beta^{2}-\frac{1-\bar{\theta}}{r(r-\bar{\theta})}\right)^{-1}
$$

Since $\bar{\theta}<1$, for $r \geq 1 \hat{\rho}$ is a strictly decreasing function of $r$. At $r=1, \hat{\rho}=\beta^{-2}>1$, so $\rho=$ $\beta^{-2}$. Lemma 1 implies that at $r=\hat{r}, \hat{\rho}=1$, so $\rho=1$. Since $\hat{\rho}$ is decreasing with $r$, for $r \geq \hat{r}$, $\hat{\rho} \leq 1$, so $\rho=1$.

Proof of Proposition 1: Equations (16) to (23) imply that $c_{1}, c_{2}, k_{0}, k_{1}, k_{2}, b$, and $m$ are proportional to $y$. Moreover, the proportional factors are positive if $\theta \in[0,1)$ and $r \in[1, \hat{r}] \subseteq$ $\left[1, \beta^{-1}\right]$. (Note $r \in[1, \hat{r}]$ implies $R \geq 1$, see $(25)$, and $\rho \in\left[1, \beta^{-2}\right]$, see Lemma 2.) In particular, we have

$$
\begin{gathered}
c_{2}=\beta r \frac{1-\beta^{2}\left(\alpha_{0} \rho+\alpha_{1}+\alpha_{2} r\right)}{1+\beta r} y, \text { and } \\
b=\beta r \frac{1-\beta^{2} \alpha_{0} \rho-\beta^{2} \alpha_{1}+\alpha_{2} \beta}{(1+\beta r)(r+1-\theta)}(1-\theta) y .
\end{gathered}
$$

Moreover, substituting (18) to (20) into (24), we obtain:

$$
y=\left[A \alpha_{0}^{\alpha_{0}} \alpha_{1}^{\alpha_{1}} \alpha_{2}^{\alpha_{1}} \beta^{2\left(\alpha_{0}+\alpha_{1}+\alpha_{2}\right)} \rho^{\alpha_{0}} r^{\alpha_{2}}\right]^{\frac{1}{1-\left(\alpha_{0}+\alpha_{1}+\alpha_{2}\right)}}
$$


Let

$$
\begin{gathered}
\psi_{0}=\beta^{3}\left(1+2 \beta+\frac{1+\beta}{1-\bar{\theta}}\right)^{-1}, \text { and } \\
\psi_{1}=2\left(4+\beta+\beta \frac{1+\beta \bar{\theta}}{1-\bar{\theta}}+(1+\beta) \sqrt{\left(\frac{\bar{\theta} \beta}{1-\bar{\theta}}\right)^{2}+\frac{4}{1-\bar{\theta}}}\right)^{-1} .
\end{gathered}
$$

The rest of the proof solves for $\theta, r, R$, and $\rho$ in each type of equilibrium, establishes that $\theta \in[0,1)$ and $r \in[1, \hat{r}]$, and shows $\psi_{0}$ and $\psi_{1}$ determine the range of parameters for which each type of equilibrium exists.

\section{Type A equilibrium}

Equations (16), (25) and (27) imply that if $\theta>\bar{\theta}$, then $R=r=1$ and $\rho=\beta^{-2}$. The existence of a type A equilibrium requires that when households and banks face these rates, they choose $k_{0}=b$, and $\theta>\bar{\theta}$. Using (22) and (23), this implies

$$
(1-\bar{\theta})\left(c_{2}+k_{2}-k_{0}\right)>k_{0}
$$

Using (18), (20), and (32), this condition is equivalent to

$$
\frac{1-\bar{\theta}}{2-\bar{\theta}} \frac{\beta}{1+\beta}\left[1-\left(\alpha_{0}+\alpha_{1} \beta^{2}+\alpha_{2} \beta^{2}\right)\right]+\alpha_{2} \beta^{2}>\alpha_{0} .
$$

Simplifying and using the definitions of $\hat{\alpha}_{0}$ and $\psi_{0}$, we obtain $\hat{\alpha}_{0}<\psi_{0}$. Finally, $\theta$ is determined by the condition $b=k_{0}$, which using $\rho=\beta^{-2},(18)$ and (33) is equivalent to

$$
\frac{\alpha_{0} \beta^{2}}{1-\alpha_{1} \beta^{2}+\alpha_{2} \beta}=\beta^{3}\left(1+2 \beta+\frac{1+\beta}{1-\theta}\right)^{-1} .
$$

All solutions to (39) must satisfy $\theta<1$. Moreover, (28) and (35), $\hat{\alpha}_{0}<\psi_{0}$, and (39) imply $\theta>\bar{\theta}$.

\section{Type B equilibrium}

By definition $b R=k_{0}$ and $\theta=\bar{\theta}$. These two conditions together with (18) and (33) imply

$$
\beta r \frac{1-\beta^{2} \alpha_{0} \rho-\beta^{2} \alpha_{1}+\alpha_{2} \beta}{(1+\beta r)(r+1-\bar{\theta})}(1-\bar{\theta}) R=\alpha_{0} \beta^{2} \rho .
$$

Using (16), (25), and the definition of $\hat{\alpha}_{0}$, we obtain the following equation, which implicitly determines $r$ :

$$
\hat{\alpha}_{0}=\beta \frac{1+\beta^{2}-\frac{1-\bar{\theta}}{r(r-\bar{\theta})}}{2 \beta+\frac{1+\beta}{r-\theta}+\frac{1-\bar{\theta}}{r(r-\bar{\theta})}} \equiv \Phi(r, \bar{\theta}) .
$$


The values of $R$ and $\rho$ follow from (16) and (25). The existence of a type B equilibrium requires that when households and banks face the rates determined by (41), (16), and (25), the borrowing constraint is binding, that is, $\rho \geq 1$, and banks are willing to hold no excess reserves, that is, $R \geq 1$. Lemma 2 together with (25) implies that a necessary and sufficient condition for the existence of a type B equilibrium is $r \in[1, \hat{r}]$, where $r$ is the solution to (41). The expression $\Phi(r, \bar{\theta})$ in $(41)$ is an increasing and differentiable function of $r$ for $r>\bar{\theta}$. Moreover, $\Phi(1, \bar{\theta})=$ $\psi_{0}$ and $\Phi(\hat{r}, \bar{\theta})=\psi_{1}$. Hence, the inverse function theorem implies that $r$ is an increasing and differentiable function of $\hat{\alpha}_{0}$. Moreover, $r \in[1, \hat{r}]$ if and only if $\hat{\alpha}_{0} \in\left[\psi_{0}, \psi_{1}\right]$.

\section{Type C equilibrium:}

By definition, $b R<k_{0}$ and $\theta=\bar{\theta}$. When the borrowing constraint is not binding, $\rho=1$, so (16) implies:

$$
\beta^{2}=r^{-1} R^{-1}
$$

Combining (25) and (42), we obtain the following quadratic equation, which implicitly determines $r$ :

$$
r^{2}-\bar{\theta} r-(1-\bar{\theta}) \beta^{-2}=0
$$

Lemma 1 provides the unique positive solution for this equation, $\hat{r}$. The values of $R$ and $\rho$

follow from (16) and (25). Since $\hat{r} \in\left(1, \beta^{-1}\right)$, (42) implies $R \in\left(\beta^{-1}, \beta^{-2}\right)$. The existence of a type $\mathrm{C}$ equilibrium requires that when households and banks face the rates determined by (43), (16) and (25), their choices satisfy $b R<k_{0}$ and $\theta=\bar{\theta}$. Banks choose $\theta=\bar{\theta}$ because $R>1$. Given (18) (33), $\theta=\bar{\theta}$, and $\rho=1$, households choose $b R<k_{0}$ if and only if

$$
\beta \hat{r} \frac{1-\beta^{2} \alpha_{0}-\beta^{2} \alpha_{1}+\alpha_{2} \beta}{(1+\beta \hat{r})(\hat{r}+1-\bar{\theta})}(1-\bar{\theta}) R<\alpha_{0} \beta^{2} .
$$

Using (25), (29), (28), and (36), expression (44) is equivalent to $\hat{\alpha}_{0}>\psi_{1}$.

Proof of Proposition 2: The definitions of $\psi_{0}$ and $\psi_{1}$ in Proposition 1 immediately imply that they are decreasing functions of $\bar{\theta}$.

If the steady-state equilibrium is type B, $r$ is determined by (41), so the implicit function theorem implies

$$
\frac{d r}{d \bar{\theta}}=-\frac{\Phi_{\bar{\theta}}(r, \bar{\theta})}{\Phi_{r}(r, \bar{\theta})} .
$$

A simple inspection of $\Phi(r, \bar{\theta})$ shows $\Phi_{r}(r, \bar{\theta})>0$. Also,

$$
\Phi_{\bar{\theta}}(r, \bar{\theta})=-\beta^{2} r \frac{1+\beta+\left(\beta^{2}-1\right) r}{[2 \beta r(r-\bar{\theta})+r(1+\beta)+1-\bar{\theta}]^{2}}<0 .
$$


Therefore, $d r / d \bar{\theta}>0$. Finally, using (25), we have

$$
\frac{d R}{d \bar{\theta}}=\frac{1}{1-\bar{\theta}} \frac{d r}{d \bar{\theta}}+\frac{r-\bar{\theta}}{(1-\bar{\theta})^{2}}>0 .
$$

If the steady-state equilibrium is type $\mathrm{C}, r$ is determined by (43), so Lemma 1 implies $d r / d \bar{\theta}>0$. Finally, using (42), we get $d R / d \bar{\theta}=-(R / r) d r / d \bar{\theta}<0$. 


\section{References}

[1] Aiyagari, S.Rao (1994), "Uninsured Idiosyncratic Risk and Aggregate Saving," Quarterly Journal of Economics, August: 659-684.

[2] Bernanke, Ben, and Mark Gertler (1987), "Banking in General Equilibrium," in New Approaches to Monetary Economics, edited by W. Barnett and K. Singleton, New York: Cambridge University Press.

[3] Bewley, Truman (1980), "The Optimum Quantity of Money," in Models of Monetary Economies, edited by John H. Kareken and Neil Wallace, Minneapolis: Federal Reserve Bank of Minneapolis: 169-210.

[4] Bewley, Truman (1983), "A Difficulty with the Optimum Quantity of Money," Econometrica 59: 1581-1589.

[5] Diamond, Douglas W. and Philip H. Dybvig (1983), "Bank Runs, Deposit Insurance, and Liquidity," Journal of Political Economy 91 (3) June: 411-419.

[6] Díaz-Giménez, Javier, Edward C. Presscott, Terry Fitzgerald, and Fernando Alvarez (1992), "Banking in Computable General Equilibrium Economies," Journal of Economic Dynamics and Control 16(3/4) July-Oct.: 533-560.

[7] Faig, Miquel (2000a), "The Optimal Structure of Liquidity Provided by a Self-Financed Central Bank," Journal of Money, Credit, and Banking 32 (4) Nov. Part 1: 746-765.

[8] Faig, Miquel (2000b), "Money with Idiosyncratic Uninsurable Returns to Capital," Journal of Economic Theory 94: 218-240.

[9] Foley D.K. and M. Hellwig (1975), “Asset Management with Trading Uncertainty,” Review of Economic Studies 42: 327-346.

[10] Holmström, Bengt, and Jean Tirole (1998), "Private and Public Supply of Liquidity," Journal of Political Economy 106 (1) Feb: 1-40.

[11] Hugget, Mark (1993), "The Risk-Free Rate in Heterogeneous-Agent Incomplete-Insurance Economies," Journal of Economic Dynamics and Control 17: 953-969. 
[12] Kiyotaki, Nobuhiro and John Moore (2001), "Liquidity, Business Cycle, and Monetary Policy," Claredon Lecture 2, manuscript

[13] Kiyotaki, Nobuhiro and John Moore (2006), "Inside Money and Liquidity," Econometrica, forthcoming.

[14] Williamson, Stephen D. (1987), "Financial Intermediation, Business Failures, and Real Business Cycle," Journal of Political Economy 95 (6) Dec.: 1196-1216.

[15] Woodford, Michael (1990), "Public Debt and Private Liquidity," American Economic Review: Papers and Proceedings of the AEA 80, May: 382-388. 
Figure 1

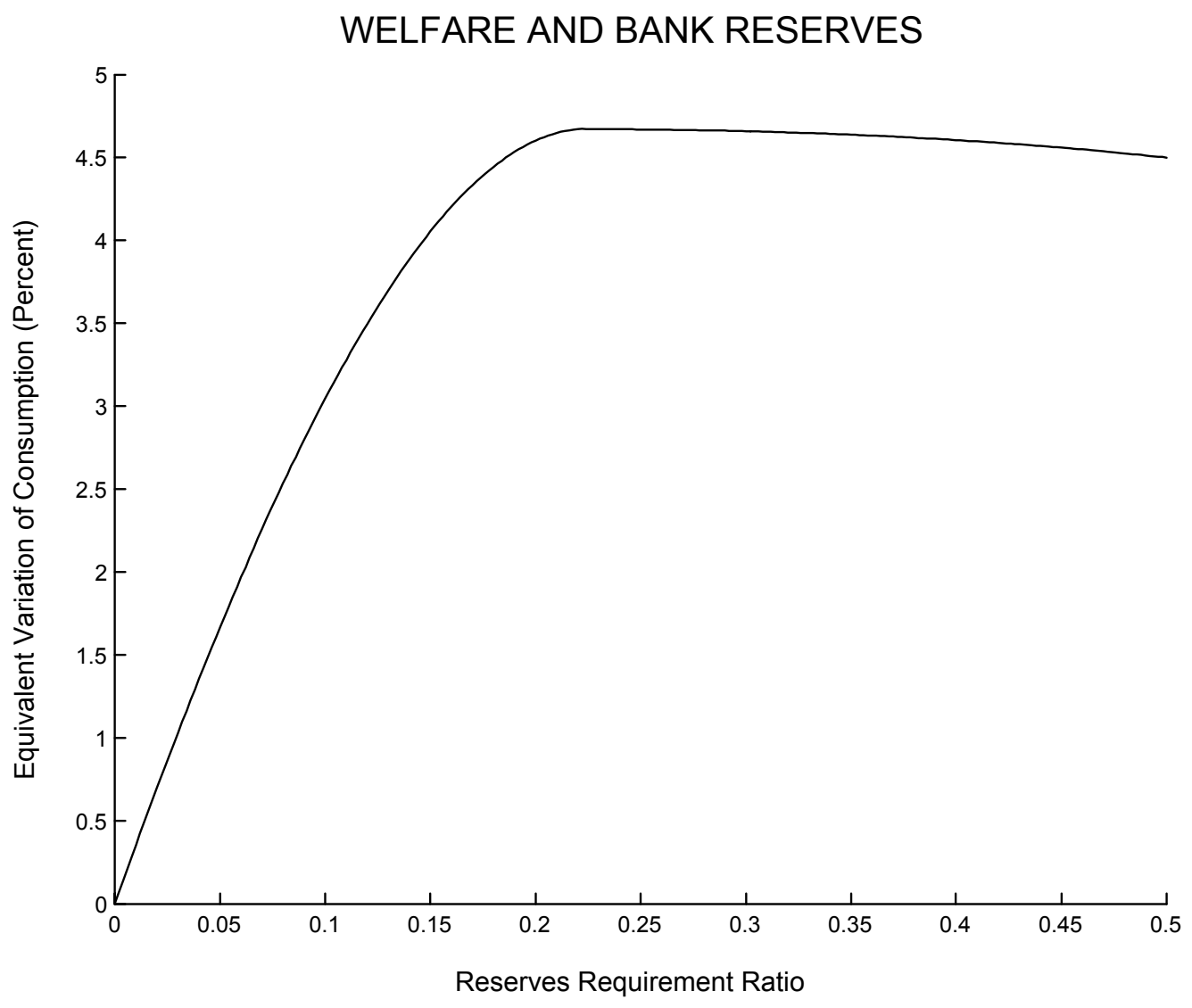

